\title{
The Surface Structure of Gold Films
}

\author{
VARIATIONS IN TOPOGRAPHY WITH METHOD OF PRODUCTION
}

\author{
Christoph Raub \\ Forschungsinstitut für Edelmetalle und Metallchemie, Schwäbisch Gmünd, West Germany
}

For most industrial applications gold is used in the form of thin layers. This is especially true for components in the electronics and telecommunication industry, where it is applied, for example, in the production of conductor networks and for many types of contacts.

The mechanical, chemical and physical properties of gold make it easy to apply to a variety of substrates, among which metals and ceramics are, of course, the most prominent. Depending on the application, and on the thickness needed, various processes for deposition are utilised, including vacuum evaporation, sputtering in an inert gas, the production of inlay contact bi-metal strip by rolling, welding, electroplating and, particularly on ceramics, deposition in finely divided form with an admixture of fluxes, the so-called thick film technology.

In the course of a research programme sponsored by the Stifterverband der Deutschen Wissenschaft a comparative investigation has been made on the properties of fine gold layers produced by thermal vacuum evaporation, radio frequency sputtering, electroplating, and rolling. Surface topography, wear resistance, porosity and annealing behaviour for layers of various thicknesses were investigated. In this brief report only the results on surface topography and its change with annealing temperature will be discussed.

\section{Experimental Details}

As a basis material $0.5 \mathrm{~mm}$ thick by $15 \mathrm{~mm}$ wide nickel strip with a hardness of $H V=110 \mathrm{kp} / \mathrm{mm}^{2}$ was used, produced on a mill with polished rolls. From this strip samples $20 \times 10 \mathrm{~mm}$ size were cut to serve as substrates for the deposition of gold. Nickel-gold inlays were produced in the usual way by cold rolling. Samples to be coated were degreased cathodically in an alkaline electrolyte and cleaned additionally for coating in vacuum by R.F. sputtering. The coating in vacuum was done by thermal evaporation of gold in a vacuum of better than $10^{-4}$ torr from a heated tungsten boat.

\section{Examination}

\section{by Electron Microscopy}

The surface structure was then investigated by electron microscopy, using a replica technique.
The micrographs show that each deposition method produces gold layers with distinct types of surface. For deposits less than $5 \mu \mathrm{m}$ thick the individual features are less pronounced but still clearly different from each other.

The rolled surface (Figure 1) is quite even, only the polishing structure of the rolls being visible with the marks running parallel to each other in the direction of rolling. There is no change in structure apparent with lower thicknesses.

The electroplated gold surface (Figure 2) shows a typical grainy structure. It is still fairly smooth, since the individual grains do not protrude markedly from their surroundings.

The surfaces of evaporated (Figure 3) and sputtered gold-films (Figure 4) present a totally different appearance. On the evaporated samples up to a thickness of about $8 \mu \mathrm{m}$ the rolling grooves on the nickel surface are still visible. The layer itself shows a homogeneous structure with small rounded grains, this becoming more pronounced with increasing thickness. Sometimes small round islets are interspersed, as if during evaporation metal had splattered out on the surface. This structure agrees nicely with that recently observed by Rehrig (1) on gold films on alumina. Whether these islets might have any connection with pore formation has yet to be investigated. On the evaporated films no grain boundaries or crystal faces could be observed.

Figure 4 shows the structure of a gold surface produced by R.F. sputtering. Even at low thicknesses a relatively rough structure appears with many peaks protruding from a basic structure. At greater thicknesses of deposit an apparently lamellar structure builds up, with rather large grains, the orientation of the lamellae being different within each grain. At higher magnifications typical growth figures are found at the faces of the lamellae. The edges themselves are rounded. The structure is very similiar to that previously observed on oxygen-etched noble metals (2) and is probably caused by an interaction between the condensation of gold atoms and the etching of the deposited layers by the bombardment of ions from the plasma. Sometimes very large crystals were found embedded in the matrix, caused by preferential grain growth. Because of the high condensation temperature the condensed gold shows 

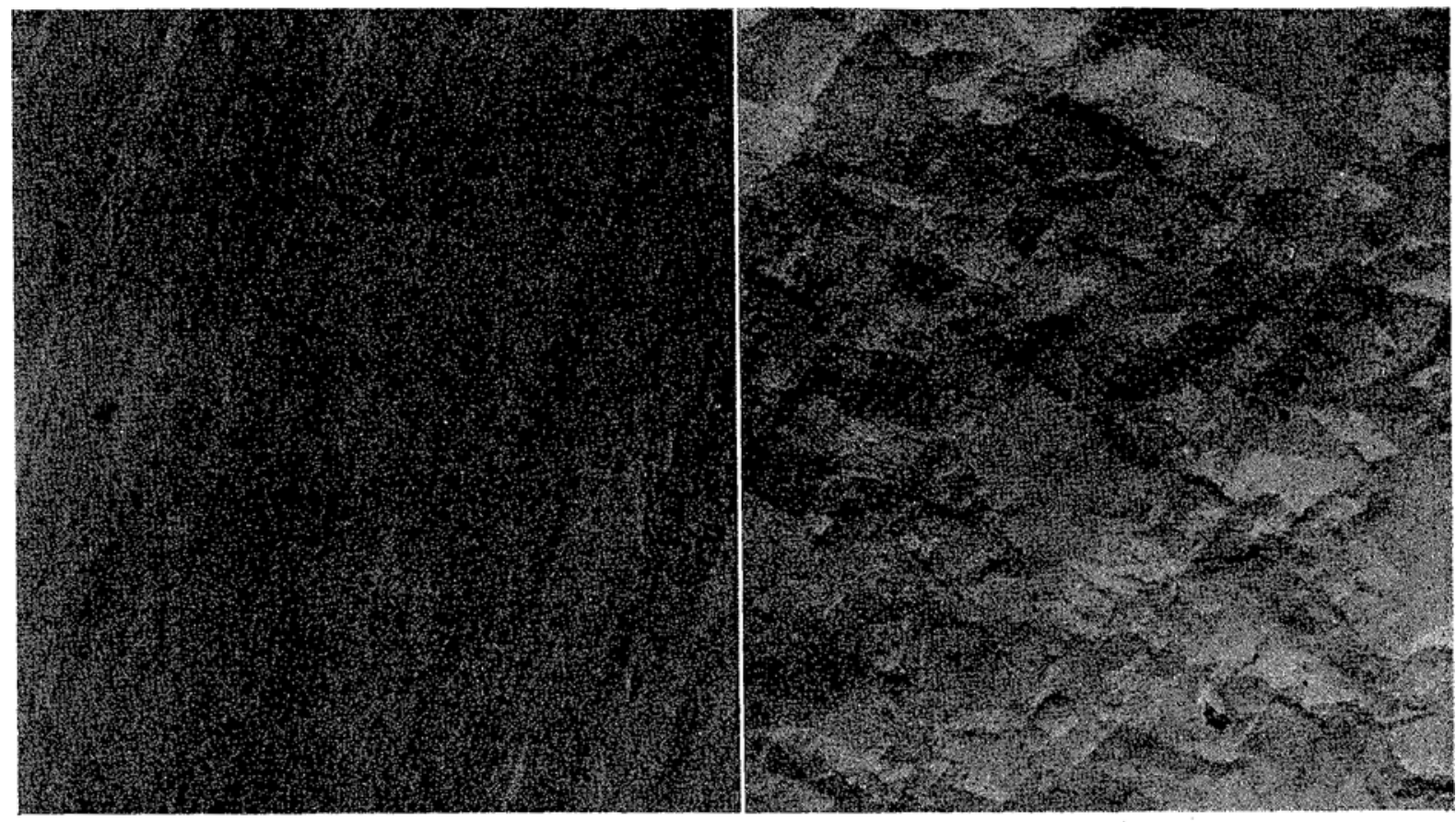

Fig. 1 Rolled

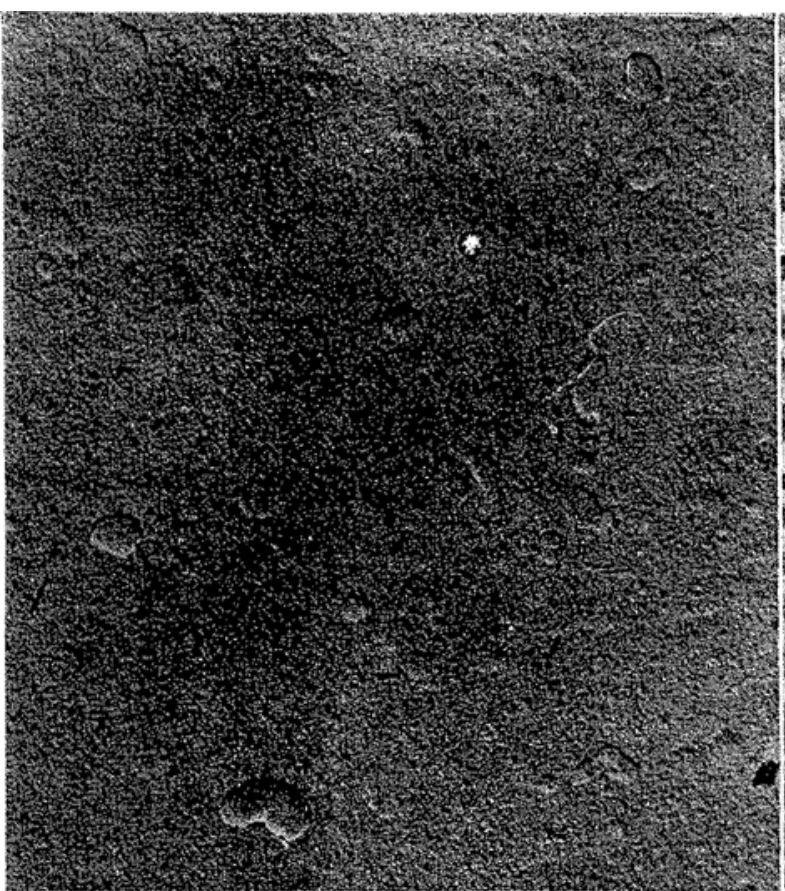

Fig. 3 Vacuum evaporated

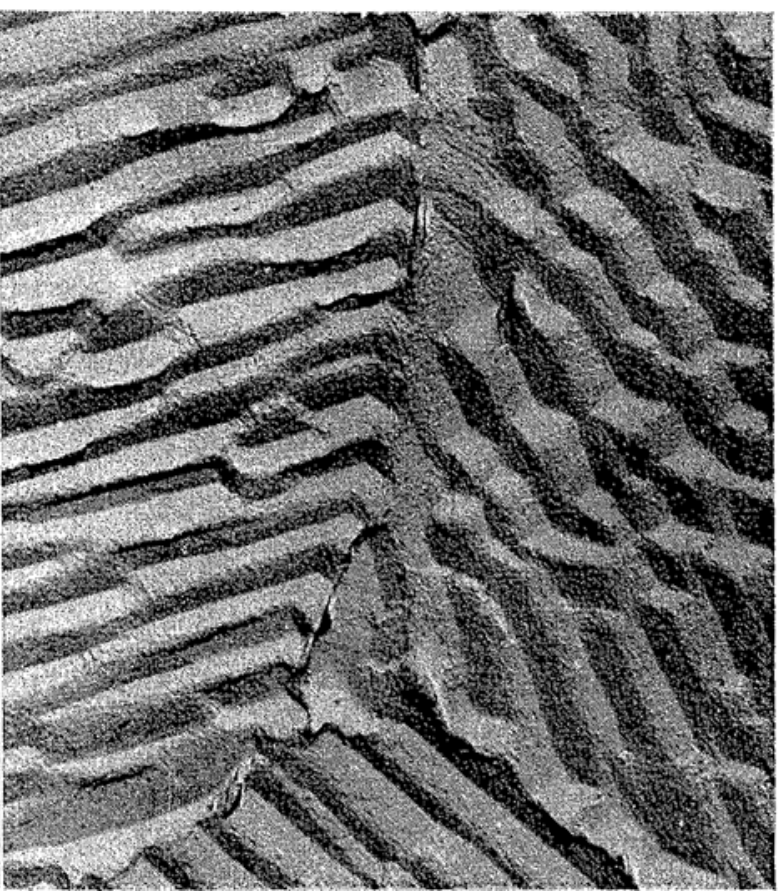

Fig. 4 R.F. sputtered

$\times 6000$

Figs. 1 to 4 The surface structure of 5 m thick gold films produced by various methods and examined by electron microscopy

the largest grain size found among all the methods investigated.

\section{Effects of \\ Heat Treatment}

Due to surface diffusion of gold atoms the appearance of the deposits changes during heat treatment between 100 and $400^{\circ} \mathrm{C}$. During this heat treatment, we tried to avoid the influence of diffusion of nickel from the basis material by using thicknesses of $5 \mu \mathrm{m}$ of gold at not too high temperatures or for long periods of time.

An attempt to anneal gold layers on quartz substrates proved unsuccessful, since the substrate had to 


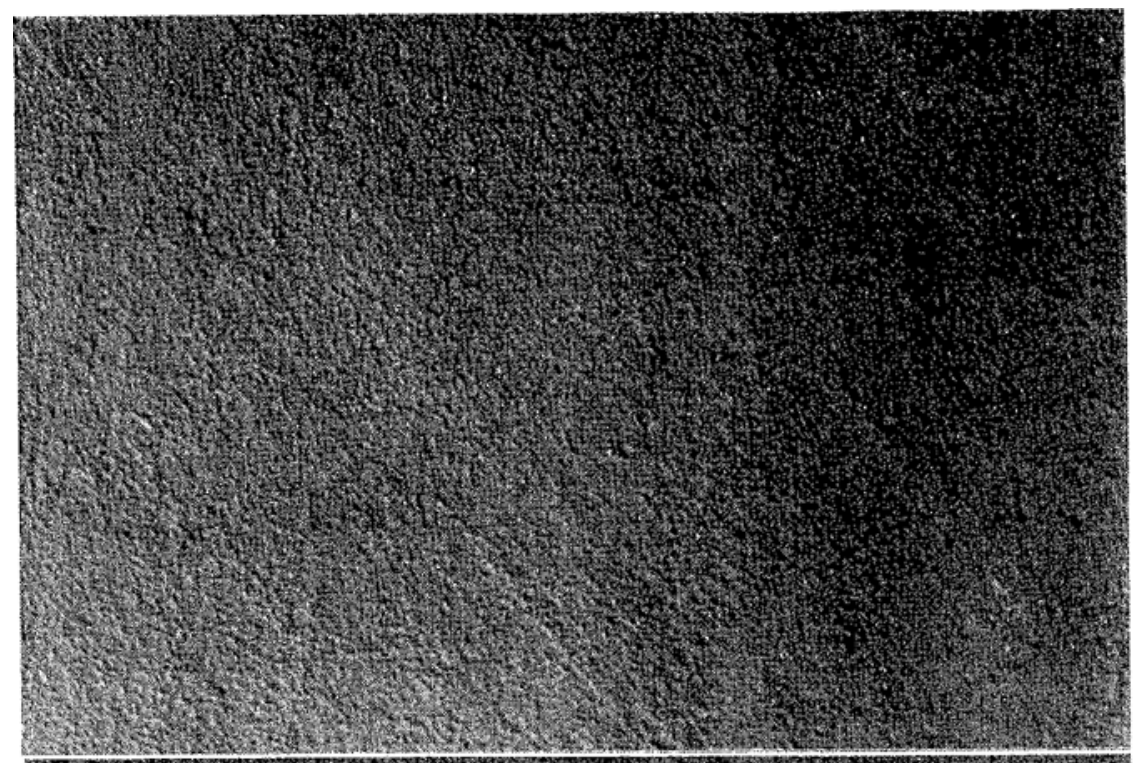

Figs. 5 and 6 The surface structure of vacuum evaporated (ahove) and sputtered (below) gold films after heat treatment in air at $400^{\circ} \mathrm{C}$ for 15 hours

$\times 6000$

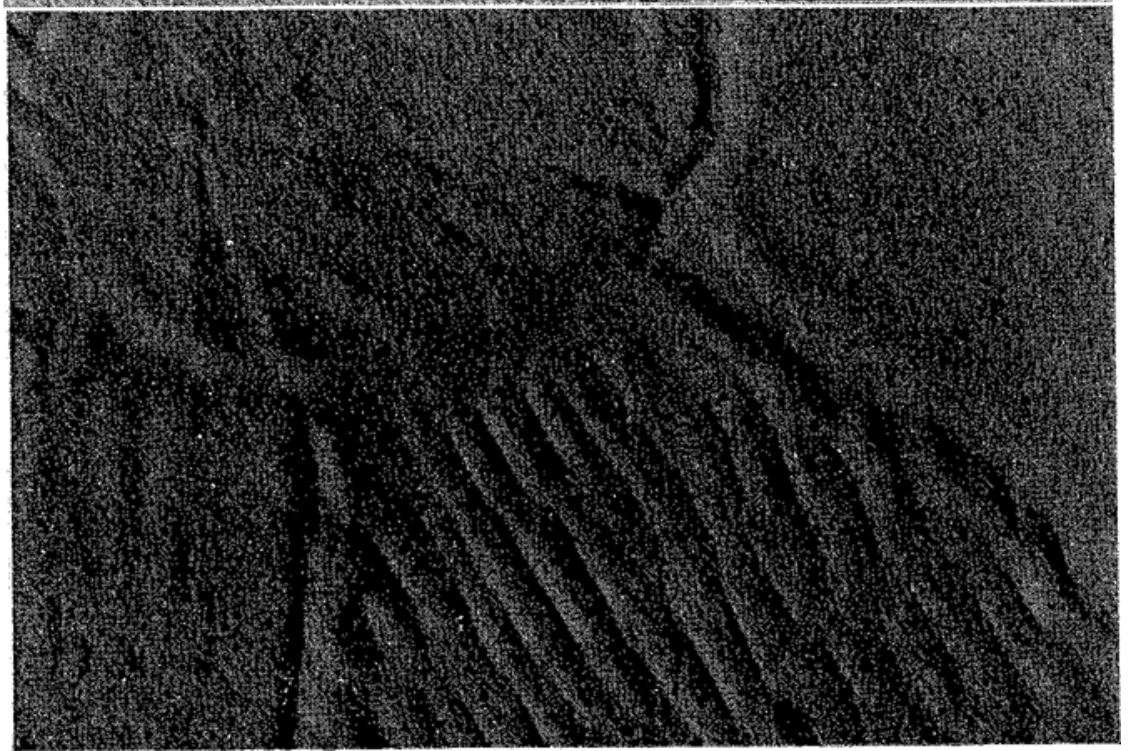

be seeded by chromium or titanium, which diffused into gold during heat treatment.

Annealing for 24 hours at $200^{\circ} \mathrm{C}$ in air caused the electroplated and evaporated gold layers to become smoother. This smoothing effect was less pronounced in sputtered layers and did not occur at all in the rolled layers. After 15 hours at $400^{\circ} \mathrm{C}$ the structure of evaporated and sputtered gold is as shown in the micrographs of Figures 5 and 6.

The small grains in the structure of the evaporated sample have grown in size, while the lamellar type structure of the sputtered surface has almost disappeared. Both surfaces seemed to be much more even after heat treatment.

The investigations show that, according to its method of deposition, each type of gold layer exhibits a typical surface structure, this structure changing rather slowly during heat treatment. It will be interesting to see how differences in structure influence other properties, such as bonding or contact behaviour, as well as porosity. In this connection the results obtained by Paatsch (3) and Rehrig (1) should be considered. Both of these workers compared the porosity of electrodeposited and evaporated nickel, chromium and gold layers. In each case the electrodeposited films showed by far the lowest porosity at thicknesses below $10 \mu \mathrm{m}$.

Rehrig attributed this to differences in the microstructure. He observed intergranular grain growth in the d.c. eecltrodeposited gold layers but not in the evaporated ones. Even greater intergranular growth is shown by pulse plated films. Up to about $3 \mu \mathrm{m}$ thickness the latter showed the least porosity.

\section{References}

1 D. L. Rehrig, Plating, 1974, 61, 43

2 E. Raub and W. Plate, Z. Metallkunde, 1957, 48, 529 3 W. Paatsch, fahrbuch Oberflächentechnik, Metall-Verlag, 1974, p. 301 